\title{
Detection of canine visceral leishmaniasis by conjunctival swab PCR
}

\author{
Vanessa Figueredo Pereira ${ }^{[1]}$, Julia Cristina Benassi ${ }^{[2]}$, \\ Wilma Aparecida Starke-Buzetti ${ }^{[3]}$, Diogo Tiago Silva ${ }^{[1]}$, Helena Lage Ferreira ${ }^{[1],[2]}$, \\ Lara Borges Keid ${ }^{[1],[2], ~ R o d r i g o ~ M a r t i n s ~ S o a r e s ~}{ }^{[1]}$, Vera Letticie de Azevedo Ruiz ${ }^{[2]}$ \\ and Trícia Maria Ferreira de Sousa Oliveira ${ }^{[1],[2]}$
}

[1]. Programa de Pós-Graduação em Epidemiologia Experimental Aplicada às Zoonoses, Faculdade de Medicina Veterinária e Zootecnia, Universidade de São Paulo, São Paulo, São Paulo, Brasil. [2]. Departamento de Medicina Veterinária, Faculdade de Zootecnia e Engenharia de Alimentos da Universidade de São Paulo, Pirassununga, São Paulo, Brasil. [3]. Departamento de Biologia e Zootecnia da Faculdade de Engenharia da Universidade Estadual Paulista, Ilha Solteira, São Paulo, Brasil.

\begin{abstract}
Introduction: Conjunctival swab PCR was evaluated as a tool to diagnose visceral leishmaniasis in dogs. Methods: Conjunctival swab PCR was compared to indirect immunofluorescence antibody test and blood PCR. Results: Indirect immunofluorescence was significantly correlated with conjunctival swab PCR $(\mathrm{p}<0.05)$, but not with blood PCR ( $p>0.05)$. In addition, conjunctival swab PCR was significantly associated with presence of clinical symptoms $(p<0.05)$, whereas blood PCR was associated with absence of clinical symptoms $(p<0.05)$. Conclusions: Results indicate that conjunctival swab PCR is useful in epidemiological surveys of canine visceral leishmaniasis.
\end{abstract}

Keywords: Canine visceral leishmaniasis. Conjunctival swab. Epidemiological survey.

Visceral leishmaniasis, a vector-borne zoonosis of global importance, is caused by the protozoan Leishmania infantum (syn. Leishmania chagasi) in Brazil( ${ }^{(1)}$. The disease is transmitted to dogs, humans, and other hosts primarily through the bite of infected sand flies ${ }^{(1)}$. It is considered a serious and chronic illness in dogs, with clinical symptoms dramatically different from one animal to another in most $\operatorname{cases}^{(1)}$. For instance, dogs may present subclinical infection that is sometimes self-limiting, or may present severe symptoms that can lead to death.

Leishmania infection may be diagnosed by several methods. For PCR-based diagnosis, DNA can be extracted from various clinical specimens, including blood, skin biopsies, lymph nodes, bone marrow, and spleen. However, collection of such specimens is invasive, and requires skilled labor or appropriate facilities. In contrast, conjunctival swabs are fast and easy to collect $^{(2)}{ }^{(3)}$. Thus, we assessed the suitability of conjunctival swabs as a biological sample for PCR-based diagnosis of canine visceral leishmaniasis. Its performance was compared to blood PCR and indirect immunofluorescence antibody test.

Blood samples and conjunctival swabs were collected between July and August 2011 from 213 dogs in Ilha Solteira $\left(20^{\circ} 25^{\prime} 58^{\prime \prime} \mathrm{S}\right.$ and $\left.51^{\circ} 20^{\prime} 33^{\prime \prime} \mathrm{W}\right)$, a city in the northwest region

Corresponding author: Dra. Trícia Maria Ferreira de Sousa Oliveira. e-mail: tricia@usp.br

Received 24 June 2015

Accepted 3 September 2015 of the Brazilian State of São Paulo. During sample collection, each dog was evaluated for clinical symptoms consistent with visceral leishmaniasis. Animals were considered to be symptomatic if at least one of the following was observed: skin disorders, apathy, lymphadenomegaly, dry fur, alopecia, onychogryphosis, erosions, ulcers, prostration, and/or cachexia $^{(1)}$. The study (Protocol No. 2203/2011) was approved by the Ethics Committee in Animal Experimentation and Animal Welfare of the Faculty of Veterinary Medicine and Animal Science from the University of Sao Paulo, and was compliant with national guidelines (Law No. 11.794, 8/10/2008).

Indirect immunofluorescence antibody test was performed according to published methods ${ }^{(4)}$ based on canine anti-IgG conjugated to fluorescein isothiocyanate (Sigma-Aldrich, Bellefonte, PA, USA, Catalog No. F7884) and diluted 1:600. Sera were considered positive when samples were fluorescently stained, with a 1:40 dilution as cutoff point ${ }^{(4)}$.

For PCR-based diagnosis, DNA was purified from conjunctival swabs and blood by phenol-chloroform ${ }^{(5)}$ and salting-out ${ }^{(6)}$, respectively. DNA was stored at $-20^{\circ} \mathrm{C}$ until analysis. A conserved $120 \mathrm{bp}$ fragment in Leishmania spp. kinetoplast DNA minicircle was amplified according to a published protocol ${ }^{(7)}$, using two pairs of primers, including primers 13A (5'-dGTG GGG GAG GGG CGT TCT-3') and 13B (5'-dATT TTA CAC CAA CCC CCA GTT-3'). Reactions consisted of 1 U Platinum ${ }^{\circledR}$ Taq DNA polymerase (Invitrogen, Camarillo, CA, USA), $15.25 \mu \mathrm{L}$ ultrapure water, $1 \times$ PCR buffer, $1.5 \mathrm{mM} \mathrm{MgCl}, 0.31 \mathrm{mM}$ each of dATP, dCTP, dGTP, 
and dTTP, $0.26 \mu \mathrm{M}$ of each primer, and $2.5 \mu \mathrm{L}$ of extracted DNA in a final volume of $25 \mu \mathrm{L}$. Positive control reactions contained DNA extracted from an in vitro culture of $L$. infantum. Negative control reactions contained DNA extracted from blood and conjunctival swabs of dogs previously confirmed to be uninfected. Amplified products were resolved on $2 \%$ agarose, stained with ethidium bromide, and photographed with a Cybershot 7.2 megapixel digital camera (DSC-W70, Sony). All samples were tested in triplicate.

To eliminate false negatives due to issues with DNA loading, sample degradation, or PCR failure, a real-time PCR reaction was performed to amplify $\beta$-actin ${ }^{(8)}$. The gene was amplified with forward primer 5'-dCTG GCA CCA CAC CTT CTA CAA-3', reverse primer 5'-dGCC TCG GTC AGC AGC A-3', and fluorogenic probe $5^{\prime}$-CCAC GCG CAG CTC G-3 ${ }^{\prime(8)}$. To construct an absolute standard curve for this reaction, canine DNA was serially diluted nine times so that each point of the curve corresponded to one log. Template DNA concentration was estimated by absorbance at 260 and $280 \mathrm{~nm}$.

Agreement between diagnostic techniques was evaluated using the kappa statistic, with values considered to indicate no agreement $(\mathrm{k}<0)$, slight $(0<\mathrm{k}<0.2)$, fair $(0.2<\mathrm{k}<0.4)$, moderate $(0.4<\mathrm{k}<0.6)$, substantial $(0.6<\mathrm{k}<0.8)$, and almost perfect $(\mathrm{k}>0.8)$ agreement ${ }^{(9)}$. Sensitivity, specificity, and confidence intervals were also calculated for all diagnostic tests, using indirect immunofluorescence as gold standard. Data were analyzed in SAS version 9.3 (SAS Institute, Inc., Cary, NC, USA) by Pearson chi-square test at $95 \%$ confidence level.

Of $213 \mathrm{dogs}$ evaluated, $28.2 \%$ (60/213) tested positive for visceral leishmaniasis on at least one of three diagnostic tests. In particular, $13.6 \%(29 / 213)$ tested positive on indirect immunofluorescence only, and $13.1 \%$ (28/213) tested positive by conjunctival swab or blood PCR only. Notably, the tests detected visceral leishmaniasis in different subsets of dogs. For example, 7.9\% (17/213) tested positive on both indirect immunofluorescence and conjunctival swab PCR, while $81.2 \%$ $(173 / 213)$ tested negative on both. In addition, $5.1 \%(11 / 213)$ of dogs were infected based on conjunctival swab PCR, while 5.6\% $(12 / 213)$ were infected based on indirect immunofluorescence. Thus, conjunctival swab PCR had sensitivity $58.6 \%$, specificity $94 \%$, positive predictive value $61 \%$, and negative predictive value $94 \%$ (Table 1).

On the other hand, 3.3\% (7/213) tested positive on both indirect immunofluorescence and blood PCR, 10.3\% (22/213) tested positive by indirect immunofluorescence only, 9.9\% (21/213) tested positive by blood PCR only, and 76.5\% (163/213) tested negative on both. Based on these data, blood PCR had sensitivity $24.1 \%$, specificity $88.5 \%$, positive predictive value $25 \%$, and negative predictive value $88 \%$ (Table 1).

Notably, the sensitivity of conjunctival swab PCR was lower than that of other diagnostic approaches based on conjunctival swabs. For instance, previous studies demonstrated sensitivity as high as $92 \%^{(5)}$, and $91.7 \%{ }^{(10)}$. In addition, $90 \%$ sensitivity was achieved by hybridization, and $83.3 \%$ by nested $\mathrm{PCR}^{(2)}$. L. infantum DNA was detected in conjunctival swabs from $95 \%$ of symptomatic dogs and $77.5 \%$ of asymptomatic dogs that also tested positive on other serological and parasitological tests $^{(3)}$. These results, however, were obtained from highly sensitive techniques. In particular, hybridization can enhance the sensitivity of PCR and verify results ${ }^{(10)}$. However, this technique requires more elaborate infrastructure to handle radioisotopes. Similarly, nested PCR has been used to enhance sensitivity, but is more time consuming and is more susceptible to contamination ${ }^{(11)}$.

In line with previous results ${ }^{(12)}$, the adjusted kappa index between indirect immunofluorescence and conjunctival swab PCR was 0.53 , suggesting moderate ${ }^{(9)}$, but statistically significant agreement ( $\mathrm{p}<0.05$, Table 2). However, the number of seronegative dogs that tested positive on conjunctival swab PCR $(n=11)$ was similar to the number of seropositive dogs that tested negative on conjunctival swab PCR $(n=12)$. This result may reflect parasite load, which may go above or below the limit of detection of each assay, depending on the phase of infection. Thus, the use of both tests would enhance diagnosis of visceral leishmaniasis in dogs.

For indirect immunofluorescence and blood PCR, the adjusted kappa index was 0.13 , indicating slight agreement ${ }^{(9)}$. Indeed, these two tests were not significantly correlated $(\mathrm{p}>0.05)$. Accordingly, blood and conjunctival swab PCR were also not significantly correlated $(p>0.05)$. These results are summarized in Table 2, and are in line with published results ${ }^{(12)}$.

TABLE 1 - Sensitivity, specificity, positive predictive value, and negative predictive value of conjunctival swab and blood PCR for canine visceral leishmaniasis, using indirect immunofluorescence antibody test as gold standard. A total of 213 dogs were tested by all three methods.

\begin{tabular}{lcc}
\hline Parameter & IFAT $\times$ CS-PCR & IFAT $\times$ blood PCR \\
\hline Sensitivity (\%) & $58.6(17 / 29)$ & $24.0(7 / 29)$ \\
Specificity (\%) & $94.0(173 / 184)$ & $88.5(163 / 184)$ \\
Positive predictive value (\%) & $61.0(17 / 28)$ & $25.0(7 / 28)$ \\
Negative predictive value (\%) & $93.5(173 / 185)$ & $88.0(163 / 185)$ \\
\hline
\end{tabular}

IFAT: immunofluorescence antibody test; PCR: polymerase chain reaction; CS-PCR: conjunctival swab- polymerase chain reaction.

TABLE 2 - Kappa agreement among indirect immunofluorescence antibody test, conjunctival swab, and blood PCR for canine visceral leishmaniasis.

\begin{tabular}{lccccccc}
\hline & \multicolumn{3}{c}{ CS-PCR } & & \multicolumn{3}{c}{ Blood PCR } \\
\cline { 2 - 4 } \cline { 6 - 8 } IFAT & + & - & total & & + & - & total \\
\hline+ & 17 & 12 & 29 & & 7 & 22 & 29 \\
- & 11 & 173 & 184 & & 21 & 163 & 184 \\
\hline Total & $\mathbf{2 8}$ & $\mathbf{1 8 5}$ & $\mathbf{2 1 3}$ & & $\mathbf{2 8}$ & $\mathbf{1 8 5}$ & $\mathbf{2 1 3}$ \\
\hline kappa & & $0.53^{*}$ & & & & 0.13 & \\
\hline
\end{tabular}

IFAT: immunofluorescence antibody test; PCR: polymerase chain reaction; CS-PCR: conjunctival swab-polymerase chain reaction. ${ }^{*} \mathrm{p}<0.05$ by chi-square test. 
Clinical symptoms were apparent in 43 dogs. Of the 29 dogs that tested positive by indirect immunofluorescence, 51.7\% $(15 / 29)$ were symptomatic. Similarly, symptoms were apparent in $57.1 \%(16 / 28)$ of dogs that tested positive by conjunctival swab PCR. In contrast, clinical symptoms were observed in only $28.6 \%(8 / 28)$ of dogs that tested positive on blood PCR. Clinical signs were also observed in $70.6 \%(12 / 17)$ of animals that tested positive on both conjunctival swab PCR and indirect immunofluorescence. Three of five animals that tested positive on all three tests were symptomatic.

Notably, statistical analysis (Table 3) indicated that a positive result on conjunctival swab PCR is significantly associated with the presence of clinical signs $(\mathrm{p}<0.05)$, while a positive result on blood PCR is significantly associated with the absence of clinical signs $(p<0.05)$. Indeed, conjunctival swab PCR has been demonstrated to have high sensitivity for Leishmania in clinically diseased ${ }^{(12)(13)}$, and asymptomatic $\operatorname{dogs}^{(2)}$. We note, however, that higher sensitivity was achieved in asymptomatic dogs by other groups ${ }^{(2)}$.

TABLE3 -Association of apositiveteston indirectimmunofluorescence, conjunctival swab PCR, and blood PCR with presence or absence of clinical symptoms.

\begin{tabular}{lccc}
\hline & \multicolumn{2}{c}{ Clinical symptoms } & \\
\cline { 2 - 3 } Positive diagnostic test & + & - & p value, $\boldsymbol{\chi}^{2}$ \\
\hline Conjunctival swab PCR & 16 & 12 & $<0.05$ \\
Blood PCR & 8 & 20 & $<0.05$ \\
IFAT & 15 & 14 & $>0.05$ \\
\hline
\end{tabular}

IFAT: immunofluorescence antibody test; PCR: polymerase chain reaction.

Because of high specificity and sensitivity, molecular techniques provide precise and accurate diagnosis of canine visceral leishmaniasis, and may identify the infecting Leishmania species. For example, blood samples were previously shown to be suitable for PCR-based diagnosis of canine visceral leishmaniasis ${ }^{(13)}$, although issues with DNA preparation and PCR failure have been reported ${ }^{(14)}$. In addition, parasite load in the blood tends to diminish over the course of infection ${ }^{(2)}$. Acceptable results were also obtained by PCR on skin samples ${ }^{(15)}$, which are, however, not easy to collect, and only through procedures that may cause pain and injury. Here, we report that conjunctival swabs are also suitable for PCR-based detection of $L$. infantum infection in dogs. In addition, conjunctival swabs are easy to collect, and thus provide opportunities for further research that may help quickly, rationally, and effectively control visceral leishmaniasis in Brazil and other countries.

\section{CONFLICT OF INTEREST}

The authors declare that there is no conflict of interest.

\section{FINANCIAL SUPPORT}

This study was funded by Fundação de Amparo à Pesquisa do Estado de São Paulo (Grant number 2011/00147-6).

\section{REFERENCES}

1. Reis AB, Martins-Filho OA, Teixeira-Carvalho A, Giunchetti RC, Carneiro CM, Mayrink W, et al. Systemic and compartmentalized immune response in canine visceral leishmaniasis. Vet Immunol Immunop 2009; 128:87-95.

2. Leite RS, Ferreira SDA, Ituassu LT, de Melo MN, de Andrade ASR. PCR diagnosis of visceral leishmaniasis in asymptomatic dogs using conjunctival swab samples. Vet Parasitol 2010; 170:201-206.

3. Ferreira SA, Leite RS, Ituassu LT, Almeida GG, Souza DM, Fujiwara RT, et al. Canine skin and conjunctival swab samples for the detection and quantification of Leishmania infantum DNA in an endemic urban area in Brazil. PLoS Negl Trop Dis 2012; 6:e1596.

4. Oliveira TMF de S, Furuta PI, de Carvalho D, Machado RZ. A study of cross-reactivity in serum samples from dogs positive for Leishmania sp., Babesia canis and Ehrlichia canis in enzymelinked immunosorbent assay and indirect fluorescent antibody test. Rev Bras Parasitol Vet 2008; 17:7-11.

5. Strauss-Ayali D, Jaffe CL, Burshtain O, Gonen L, Baneth G. Polymerase chain reaction using noninvasively obtained samples, for the detection of Leishmania infantum DNA in dogs. J Infect Dis 2004; 189:1729-1733.

6. Lahiri DK, Nurnberger JI. A rapid non-enzymatic method for the preparation of HMW DNA from blood for RFLP studies. Nucleic Acids Res 1991; 19:5444.

7. Rodgers MR, Popper SJ, Wirth DF. Amplification of kinetoplast DNA as a tool in the detection and diagnosis of Leishmania. Exp Parasitol 1990; 71:267-275.

8. Manna L, Reale S, Viola E, Vitale F, Foglia Manzillo V, Pavone LM, et al. Leishmania DNA load and cytokine expression levels in asymptomatic naturally infected dogs. Vet Parasitol 2006; 142:271-280.

9. Landis JR, Koch GG. The measurement of observer agreement for categorical data. Biometrics 1977; 33:159-174.

10. Ferreira SDA, Ituassu LT, de Melo MN, de Andrade ASR. Evaluation of the conjunctival swab for canine visceral leishmaniasis diagnosis by PCR-hybridization in Minas Gerais State, Brazil. Vet Parasitol 2008; 152:257-263.

11. Hamilton PB, Adams ER, Malele II, Gibson WC. A novel, highthroughput technique for species identification reveals a new species of tsetse-transmitted trypanosome related to the Trypanosoma brucei subgenus, Trypanozoon. Infect Genet Evol 2008; 4:26-33.

12. Di Muccio T, Veronesi F, Antognoni MT, Onofri A, Piergili Fioretti D, Gramiccia M. Diagnostic value of conjunctival swab sampling associated with nested PCR for different categories of dogs naturally exposed to Leishmania infantum infection. J Clin Microbiol 2012; 50:2651-2659.

13. Reale S, Maxia L, Vitale F, Glorioso NS, Caracappa S, Vesco G. Detection of Leishmania infantum in dogs by PCR with lymph node aspirates and blood. J Clin Microbiol 1999; 37:2931-2935.

14. Silva ES, Gontijo CM, Pirmez C, Fernandes O, Brazil RP. Short report: detection of Leishmania DNA by polymerase chain reaction on blood samples from dogs with visceral leishmaniasis. Am J Trop Med Hyg 2001; 65:896-898.

15. Quaresma PF, Murta SMF, Ferreira EC, da Rocha-Lima ACVM, Xavier AAP, Gontijo CMF. Molecular diagnosis of canine visceral leishmaniasis: identification of Leishmania species by PCR-RFLP and quantification of parasite DNA by real-time PCR. Acta Trop 2009. 